\title{
Cognitive, affective and behavioural characteristics of mothers with anxiety disorders in the context of child anxiety disorder
}

\section{Article}

Accepted Version

Creswell, C., Apetroaia, A., Murray, L. and Cooper, P. (2012) Cognitive, affective and behavioural characteristics of mothers with anxiety disorders in the context of child anxiety disorder. Journal of Abnormal Psychology, 122 (1). pp. 26-38. ISSN 1939-1846 doi: https://doi.org/10.1037/a0029516 Available at https://centaur.reading.ac.uk/28513/

It is advisable to refer to the publisher's version if you intend to cite from the work. See Guidance on citing.

To link to this article DOI: http://dx.doi.org/10.1037/a0029516

Publisher: American Psychological Association

Publisher statement: This article may not exactly replicate the final version published in the APA journal. It is not the copy of record

All outputs in CentAUR are protected by Intellectual Property Rights law, including copyright law. Copyright and IPR is retained by the creators or other copyright holders. Terms and conditions for use of this material are defined in the End User Agreement. 


\section{CentAUR}

Central Archive at the University of Reading

Reading's research outputs online 


\section{Cognitive, affective and behavioural characteristics of} mothers with anxiety disorders in the context of child anxiety disorder. Journal of Abnormal Psychology, Creswell, C., Apetroaia, A., Murray, L. and Cooper, P. (2012) 122 (1). pp. 26-38.

Dear Downloader,

Thank you for downloading this publication from our repository.

The University of Reading is committed to increasing the visibility of our research and to demonstrating the value that it has on individuals, communities, organisations and institutions.

To support us in this commitment, we are running a pilot project to find out more about the people who download information from the University of Reading website. The publication you have downloaded is part of this project.

It would help us greatly if you could spend two minutes filling out the survey at the following link. Completion is voluntary and information supplied will be treated as confidential. Please indicate if you would be happy for us to contact you in the future. Alternatively, enquiries or responses can be addressed to impact@reading.ac.uk

\section{https://www.surveymonkey.com/s/2NZ6DRL}

Thank you for your interest in our research and we look forward to receiving your feedback.

Yours sincerely

Anthony Atkin, Research Impact Manager (University of Reading) 
Cognitive, affective and behavioural characteristics of mothers with anxiety disorders in the context of child anxiety disorder

Cathy Creswell, Adela Apetroaia, Lynne Murray \& Peter Cooper

Winnicott Research Unit, School of Psychology and Clinical Language Sciences, University of Reading, Whiteknights, Reading RG6 6AL. UK

\section{Corresponding author: \\ Cathy Creswell}

Berkshire Child Anxiety Clinic, School of Psychology and Clinical Language Sciences,

University of Reading, Whiteknights, Reading RG6 6AL. UK

Telephone +44(0)118378 8926

Fax +44(0)118378 6665

Email: c.creswell@ reading.ac.uk 


\begin{abstract}
Parental emotional distress, particularly high maternal anxiety, is one of the most consistent predictors of child anxiety treatment outcome. In order to identify the cognitive, affective and behavioural parenting characteristics of mothers of children with anxiety disorders who themselves have an anxiety disorder, we assessed the expectations and appraisals of 88 mothers of anxious children (44 not anxious (NONANX) and 44 with a current anxiety disorder (ANX)) before and after interacting with their 7-12 year old children. There were no observed differences in anxiety and avoidance among children of ANX and NONANX mothers, but, compared to NONANX mothers, ANX mothers held more negative expectations and differed on observations of intrusiveness, expressed anxiety, warmth and the quality of the relationship. Associations were moderated by the degree to which children expressed anxiety during the tasks. Maternal reported negative emotions during the task significantly mediated the association between maternal anxiety status and the observed quality of the relationship. These findings suggest that maternal anxiety disorder is associated with reduced tolerance of children's negative emotions. This may interfere with the maintenance of a positive, supportive mother-child interaction under conditions of stress, and as such impede optimum treatment outcomes. The findings identify potential cognitive, affective and behavioural targets to improve treatment outcomes for children with anxiety disorders in the context of a current maternal anxiety disorder.
\end{abstract}


Cognitive, affective and behavioural characteristics of mothers with anxiety disorders in the context of child anxiety disorder

Anxiety disorders are among the most common psychological difficulties in childhood (e.g. Canino et al, 2004; Ford, Goodman, \& Meltzer, 2003). They impact substantially on children's functioning in family, social, and academic domains (e.g. Essau, Conradt, \& Petermann, 2000; Ezpeleta, Keeler, Erkanli, Costello, \& Angold, 2001), and are associated with substantial health and social costs (e.g. Bodden et al., 2008). Randomised controlled trials have consistently shown that cognitive behavioural treatments are effective for childhood anxiety disorders, with 55 to $60 \%$ of children no longer meeting criteria for an anxiety disorder following treatment (e.g. Cartwright-Hatton, Roberts, Chitsabesan, Fothergrill, \& Harringdon, 2004; James, Soler \& Weatherall, 2007). Research into factors that predict treatment outcome is at an early stage, but one of the most consistent predictors of child anxiety treatment response is parental emotional distress, in particular parental anxiety (e.g. Berman. Weems, Silverman, \& Kurtines, 2000; Bodden et al, 2008; Cobham, Dadds, \& Spence, 1998; Cooper, Gallop, Willetts, \& Creswell, 2008; Crawford, \& Manassis, 2001; Dadds, Spence, Holland, Barrett, \& Laurens, 1997; Dadds et al., 1999; Silverman, Kurtines, Pina, \& Jaccard, 2009). This association is important as rates of anxiety disorder amongst parents of anxious children have been found to be substantial in clinic populations, especially amongst mothers (e.g., Cooper, Fearn, Willetts, Seabrook, \& Parkinson, 2006; Last, Hersen, Kazdin, Francis, \& Grubb, 1987). In order to improve treatment outcomes for anxious children, a better understanding of the mechanisms by which parent anxiety maintains child anxiety is required. A necessary first step in this process is to obtain a clear understanding of the nature of the affective, cognitive and behavioural characteristics of anxious (compared to non-anxious) parents of clinically anxious children when interacting in challenging situations. 
Models of the development and maintenance of childhood anxiety disorders have proposed that particular cognitive, affective, and behavioural features of parent-child interactions maintain children's anxiety problems (e.g., Creswell, Murray, Stacey, \& Cooper, 2011). In support of this model, compared to parents of non-anxious children, parents of anxious children have been found to expect that their children's responses will be characterised by threat interpretation, negative emotions and low control (e.g., Barrett, Rapee, Dadds, \& Ryan, 1996; Creswell, Schneiring, \& Rapee, 2006; Kortlander, Kendall, \& Panichelli-Mindel, 1997; Micco \& Ehrenreich, 2008); and they view themselves as having less control over their child's responses (Wheatcroft \& Creswell, 2007). This negative cognitive style is hypothesised to drive parental emotions and behaviours that promote child anxiety by increasing parental expressed anxiety and transference of threat-related information to the child, and limiting child autonomy (Creswell et al., 2011; Hudson \& Rapee, 2004; Lester, Field, Oliver, \& Cartwright-Hatton, 2009). Empirical research has supported this account, in that studies have shown that parental fear expression, transfer of fear-relevant information, and lack of parental autonomy granting are a feature of parents of anxious, compared to non-anxious children (e.g. Mcleod, Wood, \& Weisz, 2007; Wood, McLeod, Sigman, Wang, \& Chu, 2003), and there is some experimental and longitudinal evidence for a role of each of these dimensions in the maintenance of child anxiety (e.g. de Rosnay, Cooper, Tsigaras, \& Murray, 2006; de Wilde \& Rapee, 2008; Field \& Lawson, 2003; Murray et al., 2008; Thirlwall \& Creswell, 2010). It remains unclear, however, whether these cognitive, affective and behavioural parenting styles which promote anxiety in children, are enhanced when parents themselves are also anxious. Clarification of this matter is important, as it is likely to have direct implications for improving treatment outcomes for anxious children in the context of parental anxiety. Studies that have assessed the cognitions, affect and behaviours of anxious parents have typically examined associations within nonclinical 
populations (e.g. Lester et al., 2009; van der Bruggen, Bogels \& Zeilst, 2010; Wheatcroft \& Creswell, 2007), or among anxious parents recruited on the basis of their own (and not their child's) clinical status (e.g. Ginsburg, Grover, Ialongo, 2004; Turner, Beidel, Roberson-Nay, \& Tervo, 2003; Woodruff-Borden, Morrow, Bourland, \& Cambron, 2002; Murray, Cooper, Creswell, Schofield, \& Sack, 2007; Murray et al., 2008). Few have examined the parentchild relationship in the context of anxiety disorder in both generations. This specific examination is important as it appears that the phenomenon of high parental anxiety leading to increased anxiogenic parental responses, may be especially salient when children themselves are also highly anxious (Hirshfeld, Biederman, Brody, Faraone, \& Rosenbaum, 1997).

In relation to parental expectations, Cobham and Dadds (1999) found that parents with high trait anxiety expected their children (all with anxiety disorders) to be more anxious and avoidant in a stressful task than non-anxious parents, despite the children themselves not differing in their predictions of their performance. No studies have specifically examined the affective responses of anxious versus nonanxious parents in interaction with anxious children; notably, however, Turner et al. (2003) found that anxious parents, compared to nonanxious parents, (of unselected children) reported higher peak levels of distress when interacting with their child in a risky play setting. In relation to parental behaviours, two studies have used designs which included both anxious and nonanxious parents of anxious children. Moore, Whaley and Sigman (2004) observed interactions during discussions about conflict and anxiety situations, and found that, compared to when only one or neither of a mother-child dyad were anxious, when both mother and child were anxious there was a higher frequency of maternal catastrophising comments, although there were no group differences in autonomy promotion or warmth. Gar and Hudson (2008), using a similar design, also found no significant effects of maternal anxiety, either independently or in 
interaction with child anxiety status, on measures of involvement and negativity during a speech preparation task and Five Minute Speech Sample. However, as noted by Murray et al. (2011), the findings of these studies need to be considered in the light of methodological issues relating to the assessment and coding frames applied that may account for the lack of group differences. First it appears that assessment tasks that invoke negative emotions in the child elicit more intrusive behaviours among anxious, compared to nonanxious, mothers (Hudson, Comer, \& Kendall, 2008). Second, stronger associations between parental anxiety and controlling behaviours are found with more precisely defined parental behaviours, compared to more general categories; and with performance, rather than discussion-based tasks (Murray et al, 2011; van der Bruggen, Stams \& Bogels, 2008).

The current study examined cognitive, affective, and behavioural characteristics of anxious and nonanxious mothers of clinically anxious children, taking account of the methodological issues regarding assessment methods and coding frames outlined above. First, we wanted to be sure that the tasks we were using would in fact elicit anxiety among the participating children. Thus, since children with anxiety disorders present with a range of different forms of anxiety, we observed mother-child interactions under three conditions designed to elicit child anxiety across a range of domains: that is, a social-anxiety provoking task, a performance anxiety provoking task, and a physical threat task (see procedure below for details). Second, we extended previous research with clinical samples by considering parental expectations regarding their children's responses to each task in terms of the child's performance, negative emotions and sense of control, as well as the parent's expectations regarding their own feelings and perceived control when interacting with their child. Third, we included parents' post-event ratings regarding their children's and their own response, which are of interest as performance ratings have been found to be more negative among anxious compared to nonanxious adults following the experience of a stressor (e.g. Abbott \& 
Rapee, 2004; Clark \& Wells, 1995). Fourth, in order to assess parental behaviours, we adapted a coding scheme from Murray et al. (2011) that considered specific dimensions of behaviour, informed by the wider literature (McLeod et al., 2007; Murray et al., 2007; 2008; van der Bruggen et al., 2008). Finally, we also observed child anxiety and avoidance and examined its effects on parental behaviours. Since child age and gender are likely to influence parental cognitions and behaviours (e.g. Dix, Ruble, Grusec, \& Nixon, 1986) we selected groups balanced on these factors. In addition we took account of parental mood disturbance as it is commonly comorbid with anxiety (e.g. Sartorius, Bedirhan, Lecrubier, \& Wittchen, 1996), and is associated with negative parental cognitions (e.g. Chen, Johnston, Sheeber, \& Leve, 2009) and behaviours (e.g. Lovejoy, Graczyk, O’Hare, \& Neuman, 2000).

The following hypotheses were examined among mother-child dyads in which all children met diagnostic criteria for a current anxiety disorder:

(1) Compared to nonanxious mothers, mothers with a current anxiety disorder will report more negative (pretask) expectations regarding their child's responses to a series of challenging tasks (specifically, they will anticipate that the child will have more negative feelings, poorer performance and reduced control, and that they themselves will experience more negative feelings and a reduced sense of control);

(2) Compared to nonanxious mothers, mothers with a current anxiety disorder will give more negative (posttask) appraisals (in terms of their child's and their own responses), particularly when children express high levels of anxiety during the task;

(3) Compared to nonanxious mothers, mothers with a current anxiety disorder will display increased fear expression when interacting with their children, communicate more fear-relevant information, and promote less autonomy, particularly when children express high levels of anxiety during the task; 
(4) The expectations and evaluations that are characteristic of anxious parents of anxious children, delineated above, will mediate any group differences in parental behaviours.

\section{Method}

\section{Participants}

There were 88 clinically anxious children, aged 7-12 years, and their mothers (who were all the children's primary caretakers), who took part in the study before commencing treatment. For 44 of the children, their mothers also fulfilled diagnostic criteria for a current anxiety disorder (ANX), and 44 the mothers did not (NONANX). The groups were well balanced on age, gender, ethnicity and socio-economic status (see Table 1). All participating children were recruited through referrals by local health and education service personnel to the Berkshire Child Anxiety Clinic at the University of Reading. Children were assessed by graduate psychologists using the Anxiety Disorders Interview Schedule for DSM-IC: Child and Parent version (ADIS:C/P (see below) and were included on the basis of having an anxiety disorder as their principal diagnosis. Principal anxiety disorders by group (ANX; NONANX) were as follows: Social Phobia (14\%; 11\%), Separation Anxiety Disorder (27\%; $27 \%)$, Specific Phobia (14\%; 20\%), Agoraphobia without panic disorder (5\%; 5\%),

Generalised Anxiety Disorder (32\%; 32\%), Anxiety Disorder Not Otherwise Specified (5\%; $5 \%)$. The mean number of anxiety diagnoses were $2.91(\mathrm{SD}=1.49)$ for the ANX group and $2.45(\mathrm{SD}=1.25)$ for the NONANX group. The ANX and NONANX groups did not differ significantly on children's mean number of anxiety disorders $(\mathrm{t}(86)=1.55, \mathrm{p}=.13)$ or on child or mother reported anxiety symptoms, as assessed by the Spence Children's Anxiety Scale - child and parent versions (see Table 1).

Groups were allocated on the basis of mothers' response to the Anxiety Disorders Interview Schedule for DSM-IV concerning their own current mental state. Mothers in the 
ANX group were included on the basis of having an anxiety disorder as their principal diagnosis. Principal anxiety disorders of mothers in this group were as follows: Generalised Anxiety Disorder (57\%), Social Phobia (18\%), Specific Phobia (18\%), Agoraphobia without panic disorder (5\%), Obsessive Compulsive Disorder (2\%). Mean number of anxiety diagnoses were $2.05(\mathrm{SD}=.99)$. The NONANX group were included on the basis of not meeting criteria for a current anxiety disorder. As expected, mothers in the ANX and NONANX groups differed significantly on self-reported anxiety symptoms on the Anxiety Scale of the DASS-21 (see below) $(\mathrm{t}(86)=4.98, \mathrm{p}<.001)$. They also differed significantly on self-reported level of depressed mood, assessed with the depression subscale of the DASS$21(\mathrm{t}(86)=5.67, \mathrm{p}<.001)$, see Table 1 .

\section{Procedure}

Mothers and children completed initial diagnostic interviews and symptom questionnaires either in University clinic rooms or in satellite clinics in their locality. For all families, the research assessment was conducted in a University laboratory fitted with CCTVstyle cameras. Following a 10 minute task to get settled in to the lab (a familiar game, 'Connect Four'), mothers completed questionnaires (see below) in a separate room from their child. Mothers then rejoined their child and the three tasks were administered, separated by 5 minute relaxation periods (when the mother and child watched a children's DVD together). As noted, the three challenge tasks comprised a social challenge, a performance challenge, and a physical challenge task. In the social task children were asked to give a presentation to a video-camera on a tripod manned by a research assistant. Children were told that they would be asked to give a short presentation to the video camera of 3 and 5 minutes in length. Children were given a choice of topics to talk about ('My hobbies', 'My ideal day', 'My family', 'My favourite holiday') and were told that they would be left for 5 minutes to 
prepare, with their mother's support, and they would then be asked to give the speech to the camera. For the performance task, the 'tangram' puzzles, children were asked to place geometric pieces together to form larger shapes that were outlined on a set of templates. The procedure followed Hudson and Rapee (2001) and involved presenting tangrams suitable for older children, giving a 5 minute time limit, and informing parents that this was a test of their child's thinking ability. In the physical challenge task children were presented with a black box with a hole in each of its four sides, obscured by a black curtain. Children were told that there were four 'scary items' in the black box and were invited to find out what was inside. The box contained four fluffy or squidgy toys. Mothers were present with their child throughout all the tasks and were instructed to help their child in whatever way they felt was appropriate. Maternal expectations and evaluations regarding their own responses, and their own child's, within each task were assessed using rating scales immediately before and after each task (see below).

\section{Measures}

\section{Structured diagnostic interviews with children and parents.}

Children were assigned diagnoses on the basis of the Anxiety Disorders Interview Schedule for DSM IV for Children- Child and Parent Versions (ADIS-C/P; Silverman \& Albano, 1996), a structured diagnostic interview with well established psychometric properties (Silverman, Saavedra, \& Pina, 2001). The presence or absence of a current maternal anxiety disorder diagnosis was assigned on the basis of the Anxiety Disorders Interview Schedule for DSM IV (ADIS-IV; Brown, DiNardo, \& Barlow, 2004). In both cases, where individuals met symptom criteria for a diagnosis (for the ASIS-c/p, this was based on either child or parent report) they were assigned a clinical severity rating (CSR) ranging from 0 (complete absence of psychopathology) to 8 (severe psychopathology). As is 
conventional, only those who met symptom criteria with a CSR of 4 or more (moderate psychopathology) were considered to meet diagnostic criteria. For the ADIS-C/P, as is standard, overall diagnoses and CSRs were assigned if the child met diagnostic criteria on the basis of either child or parent report, and the higher CSR of the two was taken. Assessors (psychology graduates) were trained on the administration and scoring of the ADIS and ADIS-C/P through verbal instruction, listening to assessment audio-recordings and participating in diagnostic consensus discussions. The first 20 interviews conducted were then discussed with a consensus team, led by an experienced diagnostician (Consultant Clinical Psychologist). The assessor and the consensus team independently allocated diagnoses and CSRs. Following the administration of 20 child, 20 parent interviews or 20 adult interviews, interrater reliability for each assessor was checked, and if assessors achieved reliability of at least .85 they were then required to discuss just one in six interviews with the consensus team (these ongoing checks were conducted to prevent interrater drift). Overall reliability for the team was excellent. As different assessors interviewed the parent and child simultaneously reliability figures for parent and child report were calculated separately. Reliability for presence or absence of diagnosis on the ADIS-C/P was kappa $=.98$ (child report), .98 (mother report); and for the CSR intra-class correlation $=.99$ (child report), .99 (mother report). Reliability for presence or absence of maternal diagnosis on the ADIS was kappa $=.97$; and for the CSR intra-class correlation $=.99$.

\section{Questionnaires}

Questionnaire measures were used to confirm differences and similarities between the two groups and to identify potential confounds. The Spence Children's Anxiety Scale (SCAS-c/p; Nauta et al.,2003; Spence, 1998) assessed child and parent reported child anxiety symptoms. The child version requires children to rate how often they experience each of 38 
anxiety symptoms, presented alongside six positive filler items. The SCAS-C has demonstrated high internal reliability and concurrent validity with other well known anxiety measures (e.g. the RCMAS, Spence, 1998). The Short Mood and Feelings Questionnaire (SMFQ-c; Angold et al., 1995) assessed child reported symptoms of low mood. The SMFQ$\mathrm{c}$ is a brief, 13 item measure which requires children to report how often in the past two weeks they have experienced a number of symptoms. The SMFQ-c has demonstrated high internal reliability and concurrent validity with other well known measures of symptoms of depression (e.g. the CDI; Angold et al., 1995). The conduct problems scale from the Strengths and Difficulties scale (SDQ-p; Goodman, 1997) was used to assess parent reported behavioural disturbance. The SDQ-p also is known to have good psychometric properties, and scores correlate highly with other well known scales (e.g. Rutter questionnaires, Goodman, 1997). The Depression Anxiety and Stress Scales (DASS-21; Lovibond \& Lovibond, 1995) were administered to all participating mothers and the depression and anxiety scales were used here. The DASS-21 has demonstrated good internal consistency and concurrent validity (Antony, Bieling, Cox, Enns, \& Swinson, 1998).

\section{Task expectations and evaluations}

Parents' expectations were assessed before initiating the challenge tasks. Immediately after receiving the instructions for each task, mothers were taken to a separate room and were asked to provide ratings regarding their child's and their own responses as follows: (a) how their child would feel about doing the task $(0=$ not scared at all, $10=$ extremely scared), (b) how well they thought their child would do the task $(0=$ not well at all, $10=$ extremely well $),(c)$ how much their child could do about how the task went $(0=$ nothing at all, $10=\mathrm{a}$ lot $),(\mathrm{d})$ how they would feel while their child was doing the task $(0=$ not anxious, 10 = extremely anxious), (e) how much they would be able to make a difference 
to their child's feelings about doing the task, and (f) how much they would be able to make a difference to how well their child $\operatorname{did}$ the $\operatorname{task}(0=$ not at all, $10=\mathrm{a}$ lot $)$.

Immediately following each task, mothers were asked to complete a further set of ratings regarding their evaluations of how the task went. Specifically they were asked to rate their child's (a) feelings $(0=$ not scared at all, $10=$ extremely scared $),(b)$ performance $(0=$ not well at all, $10=$ extremely well $)$, and (c) control over the task $(0=$ none at all, $10=$ a lot $)$ and their own (d) feelings during the task $(0=$ not anxious, $10=$ extremely anxious $)$, (e) control over how their child felt during the task, and (f) control over how the child did during the task $(0=$ none at all, $10=\mathrm{a}$ lot $)$.

\section{Maternal parenting behaviours}

Maternal behaviours were rated on scales developed by Murray et al. (2011), adapted to be suitable to children aged 7-12 years and to the specific tasks. Ratings were given for each minute of the mother-child interaction. Since interactions varied somewhat in duration, mean scores were calculated for each task. For each interaction dimension (see below), mean scores for each task were summed to give total scores across the full range of tasks. As in Murray et al. (2011) maternal behaviours were rated on 5 point scales, $1=$ none, $5=$ pervasive/strong, apart from promotion of avoidance ( 3 points). The behaviours rated were as follows:

1. Negative behaviours

1.1. Expressed anxiety (i.e., modelling of anxiety). Anxiety in facial expression (e.g., fearful expression, biting lip), body movements (e.g., rigid posture, wringing hands), and speech (rapid, nervous, or inhibited).

1.2. Passivity. Withdrawn and inhibited, unresponsive to child behaviour and communication (e.g., physically distant, silent). 
1.3. Promotion of avoidance. Actively encourages/supports child avoidance of task (e.g., saying 'you don't have to do it').

1.4. Over-protection. Initiates emotional and/or practical support that is not required (stroking/ kissing/ offering unnecessary help while child manages independently).

1.5. Intrusiveness. Interferes, verbally or physically, cutting across child behaviour, attempts to take over and impose own agenda.

2. Positive behaviours

2.1. Encouragement (autonomy-promotion). Provides positive motivation to child to engage in the task, showing enthusiasm regarding both task and child capacity/efforts.

2.2. Warmth. Affectionate, expresses positive regard for child, both verbally and physically.

2.3. Quality of relationship. Sense of relatedness and mutual engagement between mother and child (e.g., talking, listening, laughing and joking with each other).

3. Communication of fear relevant information

3.1. Threat promotion. Increases threat associated with task, by saying it will be unpleasant or scary in some way.

3.2. Vulnerability promotion. Highlights the child's actual or potential difficulties in completing the task by suggesting the child is vulnerable or incompetent (e.g., nervous/incapable).

\section{Children's anxious response to the tasks}

Following Murray et al. (2011), observed child anxiety during each of the three tasks was scored on a five point scale ( $1=$ absent, 5 = pervasive/strong $)$ on the basis of facial expression (e.g., fearful expression, biting lip), body movements (e.g., rigid posture, wringing hands, touching face), and speech quality (e.g., tense, or inhibited, quiet) and content (e.g., mention of being scared) during each of the three tasks. Child avoidance was also scored (1 
$=$ absent, $5=$ pervasive/strong) on the basis of the extent to which the child avoided approaching or completing the task. As for parental behaviours, ratings were given for each minute of the task and the mean scores across the three tasks were summed.

Videotapes of mother and child behaviours were scored by graduate psychologists, blind to maternal group. For each coder, in each task, a second coder independently scored a random sample of 25 videotapes. Independent coders were assigned so that all tasks were scored by overlapping coders (though for different participants, to avoid contamination) to ensure dimensions were scored similarly across tasks. Intraclass correlations showed good agreement: Maternal Expressed anxiety Mean = .77 (range $.60-.89$ across tasks/raters); Passivity Mean = $.77($ range $.60-1.00)$; Promotion of avoidance Mean $=.84($ range .62 1.00); Over-protection Mean $=.97($ range $.81-1.00)$; Intrusiveness Mean $=.85$ (range .68 $.99)$; Encouragement Mean = .76 (range $.62-.95)$; Warmth Mean = .82(range $.69-.95)$; Quality of Relationship Mean $=.81($ range $.68-.95)$; Child Expressed anxiety Mean $=$ $.75($ range $.65-.92)$; Child avoidance Mean $=.85($ range $.68-.93)$.

\section{Results}

\section{Data reduction and analytic strategy}

After examining variable distributions and removing outliers, we checked whether variables could be reduced. Variables were combined where, they related to theoretically similar dimensions and their intercorrelations indicated their combination. Thus, with regards to maternal pretask expectations, mothers' expectations of their control over their child's feelings and control over their child's performance correlated highly $(\mathrm{r}(88)=.75, \mathrm{p}<$ .001 ), and so were combined for analyses. In relation to maternal post-task evaluations, high levels of association were found between (a) maternal evaluations of the child's performance and child's control ( $\mathrm{r}(85)=.66, \mathrm{p}<.001)$, and (b) the mothers' control of child feelings and 
performance $(\mathrm{r}(85)=.72, \mathrm{p}<.001)$. These sets of variables were therefore also combined. All other variables correlated at $\mathrm{r}<.60$.

With regard to behavioural dimensions of parenting, the two dimensions of maternal positive behaviours, warmth and encouragement, correlated highly $(\mathrm{r}(88)=.65, \mathrm{p}<.001)$ and were therefore combined in to a dimension of 'positive behaviours'. All other variables were correlated at $\mathrm{r}<.60$. The correlation between child anxiety and avoidance approached this cut-off $(\rho(88)=.55, \mathrm{p}<.001)$; as the variables are conceptually so similar these were combined in to a single anxiety-avoidance variable.

To address the hypotheses relating to differences according to maternal anxiety status (hypotheses 1 - 3), multivariate analyses of variance were conducted, controlling for the extent of maternal depressed mood (DASS21). Maternal anxiety status and child expressed anxiety during the task, and their interaction were entered as independent variables, with maternal pretask expectations, posttask evaluations, or maternal behaviours during the task as the dependent variables. As the distribution of scores on overprotection, promotion of avoidance and passivity were highly skewed reflecting a bimodal distribution, these scales were dichotomised according to presence or absence of the behaviours. For these variables, binary logistic regression analyses were conducted with maternal anxiety status, child expressed anxiety during the task, extent of maternal depressed mood, and the maternal anxiety status $\mathrm{x}$ child expressed anxiety interaction entered as predictors.

Hypothesis 4 concerned mediation of the association between maternal anxiety status and behaviours, by maternal expectations and evaluations. Where significant associations were found between each of maternal group, maternal cognitions, and behaviours, the strength of the indirect path (via maternal expectations/appraisals) was examined using bootstrapped confidence intervals (Preacher \& Hayes, 2004). 


\section{Pre-task expectations}

It was hypothesised that, in comparison to nonanxious mothers, mothers with a current anxiety disorder would report more negative expectations regarding their child's and their own responses (hypothesis 1). In order to aid interpretation of the following analyses, observed child anxiety-avoidance during the task itself was compared across maternal groups, and no significant differences were found $(\mathrm{t}(86)=.47, \mathrm{p}=.64$ (anxious mothers mean $=12.45$; nonanxious mothers, mean $=12.72$ ).

For maternal expectations regarding their child's participation in the challenge tasks, there were significant effects of maternal anxiety status $\left(F(5,75)=4.41, p=.001\right.$; partial $\eta^{2}=$ $.23)$, child expressed anxiety $\left(F(5,75)=3.94, p=.003\right.$, partial $\left.\eta^{2}=.21\right)$, and their interaction $\left(\mathrm{F}(5,75)=4.23, \mathrm{p}=.002\right.$, partial $\left.\eta^{2}=.22\right)$, but not maternal depressed $\operatorname{mood}(\mathrm{F}(5,75)=$ $1.83, \mathrm{p}=.12$; partial $\left.\eta^{2}=.11\right)$. Maternal anxiety status was associated with significant differences in maternal pre-task ratings of child performance $(\mathrm{F}(1,79)=7.95, \mathrm{p}=.006$; partial $\left.\eta^{2}=.09\right)$ and maternal ratings of their own control of child feelings /performance $(\mathrm{F}(1,79)=$ 15.51, $\mathrm{p}<.001$; partial $\eta^{2}=.16$ ); see Table 2 . With the exception of maternal control of child feelings/performance $\left(F(1,79)=.45, p=.51 ;\right.$ partial $\left.\eta^{2}=.006\right)$, child expressed anxiety was significantly associated with all of the mother's pretask expectation ratings (child negative feelings $\left(\mathrm{F}(1,79)=8.06, \mathrm{p}=.006\right.$; partial $\left.\eta^{2}=.09\right)$, child performance $(\mathrm{F}(1,79)=$ 9.37, $\mathrm{p}=.003 ;$ partial $\left.\eta^{2}=.11\right)$, child control $\left(\mathrm{F}(1,79)=10.14, \mathrm{p}=.002 ;\right.$ partial $\left.\eta^{2}=.11\right)$, and maternal negative feelings $\left(\mathrm{F}(1,79)=4.39, \mathrm{p}=.04\right.$, partial $\left.\eta^{2}=.05\right)$. There was a significant interaction between maternal anxiety status and child expressed anxiety in the tasks for maternal expectations of child performance $\left(F(1,79)=6.35, p<.001\right.$; partial $\eta^{2}=$ $.07)$ and maternal expectations of control of child feelings /performance $(\mathrm{F}(1,79)=16.39, \mathrm{p}$ $<.001$; partial $\eta^{2}=.17$ ). As shown in Figure 1.1, nonanxious mothers' expectations appeared to be in line with their child's expressed anxiety during the tasks, with better ratings of 
expected performance associated with lower levels of child expressed anxiety; by contrast, anxious mothers' expectation ratings were similar whether or not their child exhibited anxiety during the task. Finally, where children expressed high anxiety in the task, this was associated with expectations of lower levels of control among nonanxious mothers, yet expectations of higher levels of control among anxious mothers (see Figure 1.2).

\section{Post-task evaluations}

For maternal posttask evaluations, there were significant effects of maternal anxiety status $\left(\mathrm{F}(4,75)=3.52, \mathrm{p}=.01 ;\right.$ partial $\left.\eta^{2}=.16\right)$, child expressed anxiety $(\mathrm{F}(4,75)=7.65, \mathrm{p}<$ .001 ; partial $\left.\eta^{2}=.29\right)$, and a significant effect of their interaction $(F(4,75)=3.97, p=.006$, partial $\left.\eta^{2}=.18\right)$. The effect of level of maternal depressed mood was not significant $(F(4,75)$ $=.83, \mathrm{p}=.51 ;$ partial $\left.\eta^{2}=.04\right)$. Anxious and nonanxious mothers differed significantly in terms of mothers' negative emotions $\left(\mathrm{F}(1,78)=4.54, \mathrm{p}=.04\right.$, partial $\left.\eta^{2}=.06\right)$ and control of child feelings/ behaviours $\left(\mathrm{F}(1,78)=10.87, \mathrm{p}=.001\right.$; partial $\left.\eta^{2}=.12\right)$, see Table 2 .

Associations with child expressed anxiety were significant for evaluations of children's negative emotions $\left(\mathrm{F}(1,78)=18.53, \mathrm{p}<.001 ;\right.$ partial $\left.\eta^{2}=.19\right)$, mother's negative emotions $\left(\mathrm{F}(1,78)=16.13, \mathrm{p}<.001 ;\right.$ partial $\left.\eta^{2}=.17\right)$, and child performance /control $(\mathrm{F}(1,78)=7.76$, $\mathrm{p}=.007$; partial $\left.\eta^{2}=.09\right)$; in all cases, high levels of expressed anxiety were associated with more negative ratings. The interaction of maternal group and child expressed anxiety was significant for mothers' negative emotions $\left(F(1,78)=6.45, \mathrm{p}=.01\right.$, partial $\left.\eta^{2}=.08\right)$ and control of child feelings / behaviours $\left(F(1,79)=11.08, p=.001 ;\right.$ partial $\left.\eta^{2}=.12\right)$. As shown in Figure 1.3, when their child did not express anxiety during the tasks, mothers with and without anxiety disorders did not differ in their own anxiety levels during the tasks, however when their child did express anxiety, mothers with anxiety disorder evidenced higher levels of anxiety than nonanxious mothers. As shown in Figure 1.4, whereas nonanxious mothers 
evidenced lower levels of perceived control when their children expressed higher anxiety during the challenge tasks, the converse was true for anxious mothers; they evidenced higher levels of perceived control when their children expressed high levels of anxiety.

\section{Maternal behaviours}

For maternal behaviours during the challenge tasks, the effect of maternal anxiety status was significant $\left(F(6,76)=2.65, p=.02 ;\right.$ partial $\left.\eta^{2}=.17\right)$, as were the effects of child expressed anxiety $\left(\mathrm{F}(6,76)=4.12, \mathrm{p}=.001\right.$; partial $\left.\eta^{2}=.25\right)$ and their interaction $(\mathrm{F}(6,76)=$ 2.71, $\mathrm{p}=.02$, partial $\left.\eta^{2}=.18\right)$. The effect of maternal depressed mood was not significant $(\mathrm{F}$ $(6,76)=1.64, p=.15 ;$ partial $\left.\eta^{2}=.12\right)$. Anxious and nonanxious mothers differed significantly in terms of intrusiveness $\left(\mathrm{F}(1,81)=8.23, \mathrm{p}=.005\right.$; partial $\left.\eta^{2}=.09\right)$, maternal expressed anxiety $\left(\mathrm{F}(1,81)=4.43, \mathrm{p}=.04\right.$; partial $\left.\eta^{2}=.05\right)$, positive behaviours $(\mathrm{F}(1,81)=$ $4.89, \mathrm{p}=.03 ;$ partial $\left.\eta^{2}=.06\right)$, and quality of relationship $\left(\mathrm{F}(1,81)=5.30, \mathrm{p}=.02 ;\right.$ partial $\eta^{2}$ $=.06)$. Child expressed anxiety was significantly associated only with quality of relationship $\left(\mathrm{F}(1,81)=10.78, \mathrm{p}=.002 ;\right.$ partial $\left.\eta^{2}=.12\right)$; however, the interaction between maternal anxiety status and child expressed anxiety was significant for intrusiveness $(\mathrm{F}(1,81)=8.87$, $\mathrm{p}=.004 ;$ partial $\left.\eta^{2}=.10\right)$, maternal expressed anxiety $\left(\mathrm{F}(1,81)=5.34, \mathrm{p}=.02 ;\right.$ partial $\eta^{2}=$ $.06)$ and quality of relationship $\left(\mathrm{F}(1,81)=4.88, \mathrm{p}=.03\right.$; partial $\left.\eta^{2}=.06\right)$. The interaction effect also approached significance for positive behaviours $(\mathrm{F}(1,81)=3.26, \mathrm{p}=.08$; partial $\left.\eta^{2}=.04\right)$. As shown in Figure 1, when children expressed more anxiety, anxious mothers were more intrusive (Figure 1.5), more anxious (Figure 1.6), and the quality of the relationship declined (Figure 1.6). For those variables that were highly skewed and were transformed into binary variables (passivity, promotion of avoidance, overprotection), there were no significant effects of maternal anxiety status, child expressed anxiety, or their interaction, although the association between degree of maternal depressed mood and 
promotion of avoidance approached significance $(\operatorname{Exp}(B)=.94, p=.09,95 \% \mathrm{CI}=.87-$ 1.01), see Table 2.

\section{Associations between maternal cognitions and behaviours}

Correlations were examined between those cognitive and behavioural variables that distinguished the maternal anxiety groups (i.e. pretask expectations of child performance, maternal control of child feelings /performance; posttask ratings of maternal negative emotions, control of child feelings/ behaviour; behavioural indices of intrusiveness, anxiety, positive behaviours, quality of relationship). As shown in Table 3 , significant associations were found between (a) mothers' pre-task expectations of control of child feelings and performance and levels of maternal intrusiveness $(r(85)=.30, \mathrm{p}=.006)$, and (c) mothers' posttask reports of their own negative emotions during the task and quality of relationship ( $\mathrm{r}$ $(85)=-.24, \mathrm{p}=.03)$. These variables were therefore explored as potential mediators of the associations between maternal anxiety status and maternal parenting behaviours on the basis of bootstrapped $(n=5000)$ confidence intervals for estimating the indirect effects (Preacher \& Hayes, 2004). For the indirect path from maternal anxiety status to behaviours via maternal pretask expectations about control of child feelings /performance, $95 \%$ confidence intervals spanned zero, and thus cannot be considered significant (mean $=.30$, s.e. $=.21,95 \%$ $\mathrm{CI}=-.12$ to .74 respectively). The indirect path from maternal anxiety status to quality of relationship via maternal posttask reports of maternal negative emotions was, however, significant $($ mean $=-.19$, s.e. $=.11,95 \% \mathrm{CI}=-.45$ to -.01$)$.

\section{Discussion}

One of the most consistent predictors of a poor response to psychological treatments for child anxiety disorders is the presence of parental psychopathology, particularly maternal 
anxiety disorder (e.g. Cooper et al., 2008; Silverman, Kurtines, Pina, \& Jaccard, 2009).

However, the cognitive and behavioural characteristics of anxious parents of anxious children have not been clearly characterised and are consequently poorly understood. We examined cognitive, affective and behavioural characteristics of anxious and nonanxious mothers of children with a current anxiety disorder and investigated whether maternal expectations and appraisals mediated the association between maternal anxiety status and observed parenting behaviours.

Our first hypothesis was supported in that, despite there being no differences in observed child anxiety and avoidance during challenge tasks, compared to nonanxious mothers, anxious mothers expected their children to perform more poorly, and anticipated that they themselves would have less control of their child's feelings and performance during the tasks. These effects were moderated by child expressed anxiety during the challenge tasks. Specifically, nonanxious mothers' expectations of their child's performance varied in line with observed levels of child anxiety-avoidance, whereas anxious mothers' predictions were stable regardless of levels of child manifest anxiety. In relation to the degree to which mothers anticipated being in control of their child's responses, anxious mothers who had children who went on to struggle in the task anticipated that they would have higher levels of control than those whose children did not struggle, and the reverse was found for nonanxious mothers (i.e. nonanxious mothers anticipated being more in control of children who did not go on to struggle in the task). These findings were unexpected and warrant further empirical examination. It remains unclear whether anxious mothers respond to child expressed anxiety with increased perceived control as a result of their shared experience of anxiety (e.g. this is an area that they feel they have particular expertise), or whether mothers may have responded to the question about how much control they would have in terms of how much they felt they should take control. It has certainly been established that highly anxious adults experience 
high levels of perceived responsibility (e.g. Salkovskis et al., 2000), and it might be anticipated that this will extend to perceived parental responsibility. This is consistent with the suggestion that anxious parents may view their child's environment in accordance with their own negative perspective of the world due to the systematic activation of hypervalent schemata, which guide cognitive processing towards negative aspects of the self and environment (Lester, Field \& Oliver, 2009).

Some support was also found for our second hypothesis. Following the child challenge tasks, anxious mothers were more likely than nonanxious mothers to rate their own emotions during the task negatively, and to make lower estimations of the degree to which they had control over their child's responses. These effects were also moderated by the degree to which the child expressed anxiety during the tasks. That is, anxious mothers reported particularly high levels of anxiety only when their child appeared to struggle in the task. In addition, and consistent with the pattern of their pretask expectations, anxious mothers reported higher levels of perceived control in the context of high, compared to low, expressed child anxiety, whereas the reverse was true for nonanxious mothers. As is discussed further below, this suggests that anxious parents may have particular difficulty tolerating their child's negative emotions, a process which is likely to promote anxiogenic parenting practices (e.g. Cheron, Ehrenreich, \& Pincus, 2009; Tiwari et al., 2008).

Our third hypothesis predicted that mothers with a current anxiety disorder would differ from nonanxious mothers in the degree to which their behaviour expressed anxiety, promoted autonomy, and communicated fear-relevant information. This hypothesis was partially supported. Specifically, compared to nonanxious mothers, anxious mothers displayed higher levels of anxiety and intrusiveness, and a poorer quality of relationship; though notably positive maternal behaviours were higher amongst anxious mothers. The association between maternal anxiety and parenting was particularly strong where children 
manifested a high level of anxiety in the task. These moderating effects may explain the lack of consistency in previous findings relating to parental behaviours in the context of maternal anxiety (e.g. van der Bruggen et al., 2008), as they suggest that studies that are conducted in low stress conditions will not be capable of eliciting differences in the behaviours of anxious and nonanxious mothers, which is consistent with our previous research (Murray et al., 2011). It is plausible that, if mothers respond to child expressions of fear or anxiety with fear, intrusiveness and negativity, as the findings of the current study indicate, this will inhibit successful child exposure to fear-inducing stimuli, a key element of cognitivebehavioural treatments for childhood anxiety (e.g. Kendall, 2011). This suggests that the critical parenting variables need to be targeted directly to improve treatment outcome for child anxiety in the context of maternal anxiety disorder. Indeed, in studies where parental behaviours have been directly targeted, the level of parental anxiety has not been found to predict child treatment outcome (e.g. Wood, Piacentini, Southam-Gerow, Chu, \& Sigman, 2006), a finding consistent with the suggestion that parenting behaviours may indeed be a mediating factor in the relationship between maternal anxiety and child anxiety treatment outcome.

Finally, there was support for our fourth hypothesis, in that mothers' reports of their own anxious feelings during the task significantly mediated the association between maternal anxiety status and the quality of the mother-child relationship. Specifically, compared to nonanxious mothers, anxious mothers were more inclined to find the experience of their child being in a challenging situation anxiety-provoking, and this accounted for the poorer quality of relationship with their child. It is also notable that maternal expectations regarding their control of their child's response was significantly associated with maternal intrusiveness (although this did not mediate the association between maternal anxiety disorder and these behaviours). It has been suggested that parents of anxious children display increased 
experiential avoidance of negative emotions; in other words, that they have a limited ability to tolerate their child's distress, and this leads to anxiogenic parental behaviours (Tiwari et al., 2008). The findings of the current study support the hypothesis that parents of anxious children who themselves have an anxiety disorder have reduced tolerance of children's negative emotions. Strategies to develop parental acceptance of negative emotions (e.g., Hayes, Strosahl, \& Wilson, 2003) may be a useful adjunct to treatments for child anxiety in the context of maternal anxiety disorder.

Some study limitations should be noted. In particular, the composition of the sample (mostly high SES, Caucasian families) limits the extent to which our findings can be generalised. Conclusions are also limited by the cross-sectional nature of the study, and our findings warrant scrutiny within prospective and experimental methodologies. The study also focussed specifically on interactions between mothers and their children; extending the investigation to consider fathers is clearly an important line for future research. While we included a range of tasks, to maximise opportunities to elicit mild stress within participants, the tasks all involved the parent-child dyad completing activities. Our failure to find differences in parental communication of fear relevant information may reflect, therefore, a reduced opportunity for discussion regarding anxiety provoking events. Further studies could do well to consider similar questions using discussion task methods, with utterance based coding (e.g., Murray et al., in submission).

In summary, the findings from the current study suggest that anxious mothers of clinically anxious children display particular cognitive, emotional, and behavioural characteristics, and that these are especially evident in conditions of elevated child anxiety. Attention to these characteristics in the treatment of childhood anxiety in the context of maternal anxiety disorder may be important in optimising child treatment outcomes. 


\section{References}

Abbott, M. J., \& Rapee, R. M. (2004). Post-event rumination and negative self-appraisal in social phobia before and after treatment. Journal of Abnormal Psychology, 113(1), 136144. doi: 10.1037/0021-843X.113.1.136

Angold, A., Costello, E. J., Messer, S. C., Pickles, A., Winder, F., \& Silver, D. (1995). Development of a short questionnaire for use in epidemiological studies of depression in children and adolescents. International Journal of Methods in Psychiatric Research, 5, 237-249.

Antony, M. M., Bieling, P. J., Cox, B. J., Enns, M. W., \& Swinson, R. P. (1998). Psychometric properties of the 42-item and 21-item versions of the Depression Anxiety Stress Scales in clinical groups and a community sample. Psychological Assessment, 10(2), 176-181. doi: 10.1037/1040-3590.10.2.176

Barrett, P. M., Rapee, R. M., Dadds, M. M., \& Ryan, S.M. (1996). Family enhancement of cognitive style in anxious and aggressive children. Journal of Abnormal Child Psychology, 24(2), 197-203.

Berman, S. L., Weems, C. F., Silverman, W. K., \& Kurtines, W.M. (2000). Predictors of outcome in exposure-based cognitive and behavioral treatments for phobic and anxiety disorders in children. Behavior Therapy, 31, 713-731.

Bodden, D. H. M., Bögels, S. M. Nauta, M. H., De Haan, E. Ringrose, J., Appelboom, C.,...Appelboom-Geerts, K. C. M. M. J. (2008). Child versus family cognitivebehavioral therapy in clinically anxious youth: An efficacy and partial effectiveness study. Journal of the American Academy of Child \& Adolescent Psychiatry, 47(12), 1384-1394. 
Bodden, D. H. M., Dirksen, \& C. D., Bögels, S. M. (2007). Societal burden of clinically anxious youth referred for treatment: a cost-of-illness study. Journal of Abnormal Child Psychology, 36, 487-497.

Brown, T. A., DiNardo, P., \& Barlow, D. H. (2004). Anxiety disorders interview schedule adult version (ADIS-IV): Client interview schedule: Set of 10 (Treatments that work). USA: Oxford University Press.

Canino, G., Shrout,P. E., Rubio-Stipec, M., Bird, H. R., Bravo, M., Ramírez, R., Chavez, L., Alegría, M.,... Martínez-Taboas, A.M.A. (2004). The DSM-IV rates of child and adolescent disorders in Puerto Rico: Prevalence, correlates, service use, and the effects of impairment. Archives of General Psychiatry, 61, 85-93.

Cartwright-Hatton, S., Roberts, C., Chitsabesan, P., Fothergill, C., \& Harrington, R. (2004). Systematic review of the efficacy of cognitive behaviour therapies for childhood and adolescent anxiety disorders. British Journal of Clinical Psychology, 43(4), 421-436.

Chen, M., Johnston, C., Sheeber, L., \& Leve, C. (2009). Parent and adolescent depressive symptoms: The role of parental attributions. Journal of Abnormal Child Psychology, 37(1), 119-130.

Cheron, D., Ehrenreich, J., \& Pincus, D. (2009). Assessment of parental experiential avoidance in a clinical sample of children with anxiety disorders. Child Psychiatry \& Human Development 40(3), 383-403.

Clark, D. M., \& Wells, A. (1995). A cognitive model of social phobia. In Heimberg. R. G., Liebowitz, M. R., Hope, D. A., \& Schneier, F. R. (Eds.), Social Phobia: Diagnosis, assessment and treatment (pp. 69 - ?). New York: The Guilford Press. 
Cobham, V. E. and Dadds, M. R. (1999). Anxious children and their parents: What do they expect? Journal of Clinical Child Psychology, 28(2), 220-231.

Cobham, V. E., Dadds, M. R., \& Spence, S. H. (1998). The role of parental anxiety in the treatment of childhood anxiety. Journal of Consulting and Clinical Psychology 66(6), 893-905.

Cooper, P.J., Fearn, V., Willetts, L., Seabrook, H., \& Parkinson, M. (2006). Affective disorder in the parents of a clinic sample of children with anxiety disorders. Journal of Affective Disorder, 93, 205-212.

Cooper, P.J., Gallop, C., Willetts, L., \& Creswell, C. (2008). Treatment response in child anxiety is differentially related to the form of maternal anxiety disorder. Behavioural and Cognitive Psychotherapy, 36, 41-48.

Crawford, A. M., and Manassis, K. (2001). Familial predictors of treatment outcome in childhood anxiety disorders. Journal of the American Academy of Child and Adolescent Psychiatry, 40(10), 1182-1189.

Creswell, C., Murray, L., Stacey, J., \& Cooper, P. (2011). Parenting and child anxiety. In W.K. Silverman \& A.P. Field (Eds.), Anxiety disorders in children and adolescents, (pp. 299-322). Cambridge: Cambridge University Press.

Creswell, C., Schniering, C. A., \& Rapee, R. M. (2005). Threat interpretation in anxious children and their mothers: comparison with nonclinical children and the effects of treatment. Behaviour Research and Therapy, 43(10), 1375-1381.

Dadds, M. R., Holland, D. E., Spence, S. H., Laurens, K. R., Mullins, M., and Barrett, P. M. (1999). Early intervention and prevention of anxiety disorders in children: Results at 2year follow-up. Journal of Consulting and Clinical Psychology, 67(1), 145-150. 
Dadds, M. R., Spence, S. H., Holland, D. E., Barrett, P. M., and Laurens, K. R. (1997). Prevention and early intervention for anxiety disorders: A controlled trial. Journal of Consulting and Clinical Psychology, 65(4), 627-635.

de Rosnay, M., Cooper, P. J., Tsigaras, N., \& Murray, L. (2006). Transmission of social anxiety from mother to infant: An experimental study using a social referencing paradigm. Behaviour Research and Therapy, 44(8), 1165-1175.

de Wilde, A., \&. Rapee, R. M (2008). Do controlling maternal behaviours increase state anxiety in children's responses to a social threat? A pilot study. Journal of Behavior Therapy and Experimental Psychiatry, 39(4), 526-537.

Dix, T., Ruble, D. N., Grusec, J. E., \& Nixon, S. (1986). Social Cognition in Parents: Inferential and Affective Reactions to Children of Three Age Levels, Child Development, 57(4), 879-894.

Essau, C. A., Conradt, J., \& Petermann, F. (2000). Frequency, comorbidity, and psychosocial impairment of anxiety disorders in German adolescents. Journal of Anxiety Disorders, 14(3), 263-279.

Ezpeleta, L., Keeler, G. Erkanli, A., Costello, E. J., \& Angold, A. (2001). Epidemiology of Psychiatric Disability in Childhood and Adolescence. Journal of Child Psychology and Psychiatry, 42(7), 901-914.

Field A. P., \& Lawson, J. (2003), Fear information and the development of fears during childhood: effects on implicit fear responses and behavioural avoidance. Behaviour Research and Therapy, 41(11), 1277-1293. 
Ford, T., Goodman, R., \& Meltzer, H. (2003). The British child and adolescent mental health survey 1999: The prevalence of DSM-IV disorders. Journal of the American Academy of Child Adolescent Psychiatry, 42(10), 1203-1211.

Gar, N. S., \& Hudson, J. L. (2008). An examination of the interactions between mothers and children with anxiety disorders. Behaviour Research and Therapy 46(12), 1266-1274.

Ginsburg, G. S., Grover, R. L., Ialongo, N. (2004). Parenting behaviors among anxious and non-anxious mothers: Relation with concurrent and long-term child outcomes. Child \& Family Behavior Therapy, 26(4), 23-41.

Goodman, R. (1997). The strengths and difficulties questionnaire: A research note. Journal of Child Psychology and Psychiatry, 38, 581-586.

Hirshfeld, D. R., Biederman, J., Brody, L., Faraone, S. V., \& Rosenbaum, J. F. (1997). Expressed emotion toward children with behavioral inhibition: Associations with maternal anxiety disorder. Journal of the American Academy of Child \& Adolescent Psychiatry, 36(7), 910-917.

Hayes, S. C., Strosahl, K. D., \& Wilson, K. G. (2003). Acceptance and commitment therapy: An experiential approach to behavior change. New York: The Guilford Press.

Hudson, J. L., Comer, J. S., \& Kendall, P. C. (2008). Parental responses to positive and negative emotions in anxious and nonanxious children. Journal of Clinical Child \& Adolescent Psychology, 37(2), 303-313.

Hudson, J. L., \& Rapee, R. M. (2001).Parent-child interactions and anxiety disorders: an observational study. Behaviour Research and Therapy, 39(12), 1411-1427. 
Hudson, J. L., \& Rapee, R. M. (2004). From anxious temperament to disorder: an etiological model. In R.G. Heimberg, C.L. Turk, D.S. Mennin (Eds). Generalized `Anxiety Disorder: Advances in research and practice. (pp. 51- 75). New York: Guilford Press.

James, A., Soler, A., \& Weatherall, R. (2007). Cochrane review: Cognitive behavioural therapy for anxiety disorders in children and adolescents. Evidence-Based Child Health: A Cochrane Review Journal 2(4), 1248-1275.

Keeler, G., Erkanli, A. E., Costello, J., \& Angold, A. (2001). Epidemiology of psychiatric disability in childhood and adolescence, Journal of Child Psychology and Psychiatry, 42(7), 901-914.

Kendall, P. C. (2011) Anxiety disorders in youth. In P. C. Kendall (Ed.), Child and adolescent therapy: Cognitive-behavioural procedures (pp. 143-189). New York: Guilford Press.

Kortlander, E., Kendall, P. C., \& Panichelli-Mindel, S. M. (1997). Maternal expectations and attributions about coping in anxious children. Journal of Anxiety Disorders, 11(3), 297315.

Last, C.G., Hersen, M., Kazdin, A.E., Francis, G., \& Grubb, H.J., (1987) Psychiatric illness in the mothers of anxious children. American Journal of Psychiatry, 144, 1580-1583.

Lester, K. J., Field, A. P., Oliver, S., \& Cartwright-Hatton, S. (2009). Do anxious parents interpretive biases towards threat extend into their child's environment? Behaviour Research and Therapy, 47(2), 170-174.

Lovejoy, M. C., Graczyk, P. A., O'Hare, E., \& Neuman, G. (2000). Maternal depression and parenting behavior: A meta-analytic review. Clinical Psychology Review, 20(5), 561592. 
Lovibond, S. H., \& Lovibond, P. F. (1995). Manual for the Depression Anxiety Stress Scales (2nd ed.). Sydney: Psychology Foundation (Available from The Psychology Foundation, Room 1005 Mathews Building, University of New South Wales, NSW 2052, Australia)

McLeod, B. D., Wood, J. J., \& Weisz, John R. (2007). Examining the association between parenting and childhood anxiety: A meta-analysis. Clinical Psychology Review. 27(2), 155-172.

Micco, J. A., \& Ehrenreich J. T. (2008). Children's interpretation and avoidant response biases in response to non-salient and salient situations: Relationships with mothers' threat perception and coping expectations. Journal of Anxiety Disorders, 22(3), 371385.

Moore, P. S., Whaley, S. E., \& Sigman, M. (2004). Interactions Between Mothers and Children: Impacts of Maternal and Child Anxiety. Journal of Abnormal Psychology, $113(3), 471-476$.

Murray, L., Cooper, P. J., Creswell, C., Schofield, E., \& Sack, C. (2007). The effects of maternal social phobia on mother-infant interactions and infant social responsiveness Journal of Child Psychology and Psychiatry, 48(1), 45-52.

Murray, L., de Rosnay, M., Pearson, J., Bergeron, C., Schofield, L., Royal-Lawson, M. \& Cooper, P.J. (2008). Intergenerational transmission of social anxiety: the role of social referencing processes in infancy. Child Development, 79(4), 1049-1064.

Murray, L., Lau, P.Y., Arteche, A., Creswell, C., Russ, S., Della Zoppa, L., Muggeo, M.,...Cooper, P. (2011). Parenting by anxious mothers: effects of disorder subtype, 
context, and child characteristics. Journal of Child Psychology and Psychiatry, 53(2), 188-196.

Murray et al. (2012). Socially anxious mothers' narratives to their children concerning starting school, and their relation to child representations and adjustment. Manuscript submitted for publication.

Nauta, M. H., Scholing, A., Rapee, R. M., Abbott, M., Spence, S. H., \& Waters, A. (2004). A parent-report measure of children's anxiety: psychometric properties and comparison with child-report in a clinic and normal sample. Behaviour Research and Therapy, 42, 813-839.

Preacher, K. J., \& Hayes, A. F. (2004). SPSS and SAS procedures for estimating indirect effects in simple mediation models. Behavior Research Methods, Instruments, \& Computers, 36, 717-731.

Salkovskis, P. M., Wroe, A. L. Gledhill, A., Morrison, N., Forrester, E., Richards, C.,... Thorpe, S. (2000). Responsibility attitudes and interpretations are characteristic of obsessive compulsive disorder. Behaviour Research and Therapy, 38(4), 347-372.

Sartorius, N., Bedirhan, A. T., Lecrubier, Y., \& Wittchen, H. (1996). Depression comorbid with anxiety: Results from the WHO study on "Psychological disorders in primary health care. British Journal of Psychiatry, 168(Suppl 30), 38-43.

Silverman, W. K., \& Albano, A. M. (1996). The Anxiety Disorders Interview Schedule for Children for DSM-IV: Child and Parent Versions. San Antonio, TX: Psychological Corporation. 
Silverman, W.K., Kurtines, W.M., Pina, A.A., \& Jaccard, J. (2009). Directionality of change in youth anxiety treatment involving parents: An initial examination. Journal of Consulting and Clinical Psychology, 77, 474-485.

Silverman, W. K., Saavedra, L. M., \& Pina, A. A. (2001). Test-retest reliability of anxiety symptoms and diagnoses with the Anxiety Disorders Interview Schedule for DSM-IV: child and parent versions. Journal of the American Academy of Child \& Adolescent Psychiatry, 40, 937-944.

Spence, S. H. (1998). A measure of anxiety symptoms among children. Behaviour Research and Therapy, 36, 545-566.

Tiwari, S., Podell, J. C., Martin, E. D., Mychailyszyn, M. P., Furr, J. M., Kendall, P. C. (2008). Experiential avoidance in the parenting of anxious youth: Theory, research, and future directions. Cognition \& Emotion, 22(3), 480-496.

Thirlwall, K., \& Creswell, C. (2010). The impact of maternal control on children's anxious cognitions, behaviours and affect: An experimental study. Behaviour Research and Therapy, 48(10), 1041-1046.

Turner, S. M., Beidel, D. C., Roberson-Nay, R., \& Tervo, K. (2003). Parenting behaviors in parents with anxiety disorders. Behaviour Research and Therapy, 41(5), 541-554.

van der Bruggen, C. O., Bögels, S. M., \& van Zeilst, N.(2009). What influences parental controlling behaviour? The role of parent and child trait anxiety. Cognition \& Emotion, 24(1), 141-149.

van der Bruggen, C. O., Stams, G. J. J. M., \& Bögels, S. M. (2008). Research Review: The relation between child and parent anxiety and parental control: a meta-analytic review. Journal of Child Psychology and Psychiatry, 49(12), 1257-1269. 
Wheatcroft, R. \& Creswell, C. (2007). Parents' cognitions and expectations about their preschool children: The contribution of parental anxiety and child anxiety. British Journal of Developmental Psychology, 25(3), 435-441.

Wood, J. J., McLeod, B. D., Sigman, M., Wang, W. C., \& Chu, B. C. (2003). Parenting and childhood anxiety: theory, empirical findings, and future directions. Journal of Child Psychology and Psychiatry, 44(1), 134-151.

Wood, J. J., Piacentini, J. C. Southam-Gerow, M., Chu, B. C., \& Sigman, M. (2006). Family cognitive behavioral therapy for child anxiety disorders. Journal of the American Academy of Child Adolescent Psychiatry, 45(3), 314-321.

Woodruff-Borden, J., Morrow, C., Bourland, S., \& Cambron, S. (2002). The behavior of anxious parents: Examining mechanisms of transmission of anxiety from parent to child. Journal of Clinical Child \& Adolescent Psychology, 31(3), 364-374. 
Table 1

Sample Characteristics

\begin{tabular}{|c|c|c|c|}
\hline & $\begin{array}{l}\text { Anxious mothers } \\
\qquad \mathrm{N}=44\end{array}$ & $\begin{array}{l}\text { Nonanxious mothers } \\
\qquad \mathrm{N}=44\end{array}$ & \\
\hline $\begin{array}{l}\text { Age } \\
(\text { mean, SD) }\end{array}$ & $9.64(1.30)$ & $9.39(1.51)$ & $\mathrm{t}(86)=.83, \mathrm{p}=.41$ \\
\hline $\begin{array}{l}\text { Gender } \\
(\%(\mathrm{n}) \text { female) }\end{array}$ & $61.40(27)$ & $59.10(26)$ & $\chi^{2}(1)=.05, p=.83$ \\
\hline $\begin{array}{l}\text { Family SES } \\
\%(\mathrm{n}) \text { 'Higher } \\
\text { professional' }\end{array}$ & $61.36(27)$ & $70.45(31)$ & $\chi^{2}(1)=.81, p=.37$ \\
\hline $\begin{array}{l}\text { Ethnicity } \\
\% \text { (n) White British }\end{array}$ & 84.09 (37) & $79.55(35)$ & $\chi^{2}(1)=.31, p=.58$ \\
\hline $\begin{array}{l}\text { SCAS-c } \\
\text { Total (mean, SD) }\end{array}$ & 43.05 (19.94) & $39.07(15.88)$ & $\mathrm{t}(86)=1.04, \mathrm{p}=.30$ \\
\hline $\begin{array}{l}\text { SCAS-p } \\
\text { Total (mean, SD) }\end{array}$ & $39.06(14.45)$ & $36.93(18.64)$ & $\mathrm{t}(75)=.55, \mathrm{p}=.58$ \\
\hline $\begin{array}{l}\text { SDQ }-\mathrm{p} \\
\text { Conduct problems } \\
\text { (mean, SD) }\end{array}$ & $3.07(1.78)$ & $3.07(1.78)$ & $\mathrm{t}(85)=1.09, \mathrm{p}=.28$ \\
\hline $\begin{array}{l}\text { SMFQ-c } \\
(\text { mean, SD) }\end{array}$ & $7.82(4.93)$ & $7.93(5.90)$ & $\mathrm{t}(86)=.10, \mathrm{p}=.92$ \\
\hline $\begin{array}{l}\text { DASS } \\
\text { Anxiety (mean, SD) }\end{array}$ & $8.41(7.58)$ & $2.36(2.74)$ & $\mathrm{t}(86)=4.98, \mathrm{p}<.001$ \\
\hline
\end{tabular}




\begin{tabular}{|l|l|l|l|}
\hline DASS & & \\
Depression (mean, & $12.23(8.80)$ & $3.77(4.53)$ & $\mathrm{t}(86)=5.67, \mathrm{p}<.001$ \\
SD) & & \\
\hline
\end{tabular}


Table 2

Maternal anxiety group differences in expectations, appraisals and behaviours

\begin{tabular}{|c|c|c|c|c|}
\hline & & $\begin{array}{l}\text { Anxious mothers } \\
\qquad \mathrm{N}=44\end{array}$ & $\begin{array}{l}\text { Nonanxious } \\
\text { mothers } \\
\mathrm{N}=44\end{array}$ & $\mathrm{~F}$ \\
\hline \multicolumn{5}{|c|}{ Pretask expectations of child response } \\
\hline Pretasks child feeling & & $14.73(4.48)$ & $13.86(5.09)$ & 0.03 \\
\hline Pretask child perform & & $20.73(3.41)$ & $22.07(4.28)$ & $7.95 * *$ \\
\hline $\begin{array}{l}\text { Pretask child control } \\
\text { performance }\end{array}$ & & $18.61(4.36)$ & $20.37(4.60)$ & 1.59 \\
\hline \multicolumn{5}{|c|}{ Pretask expectations of mother response } \\
\hline $\begin{array}{l}\text { Pretasks mother feeli } \\
\text { when child doing tas }\end{array}$ & & $12.95(3.92)$ & $10.32(4.58)$ & 0.07 \\
\hline $\begin{array}{l}\text { Pretasks: Mother con } \\
\text { child feelings and } \\
\text { performance }\end{array}$ & & $32.73(10.41)$ & $34.19(10.74)$ & $15.51 * * *$ \\
\hline \multicolumn{5}{|c|}{ Posttask evaluations of child response } \\
\hline $\begin{array}{l}\text { Child negative } \\
\text { emotions }\end{array}$ & & $3.29(5.51)$ & $11.78(5.71)$ & 0.94 \\
\hline $\begin{array}{l}\text { Child performance } \\
\text { and control }\end{array}$ & & $1.95(7.76)$ & $43.29(8.80)$ & 1.83 \\
\hline \multicolumn{5}{|c|}{ Posttask evaluations of mother response } \\
\hline
\end{tabular}




\begin{tabular}{|l|c|c|c|}
\hline Mother control of & & \\
child feelings and & $30.02(10.12)$ & $31.05(12.75)$ & $11.36^{* *}$ \\
performance & $11.26(6.07)$ & $8.34(4.62)$ & $3.88 \dagger$ \\
\hline Mother negative & & & \\
\hline
\end{tabular}

\begin{tabular}{|c|c|c|c|}
\hline \multicolumn{4}{|l|}{ Parental behaviours } \\
\hline Expressed anxiety & $9.93(2.05)$ & $9.08(2.25)$ & $4.43^{*}$ \\
\hline Intrusiveness & $6.78(1.92)$ & $6.52(1.47)$ & $8.23 * *$ \\
\hline Positive behaviours & $24.28(4.00)$ & $23.55(3.3)$ & $4.89 *$ \\
\hline $\begin{array}{l}\text { Quality of } \\
\text { Relationship }\end{array}$ & $9.40(1.57)$ & $9.51(1.08)$ & $5.30 *$ \\
\hline Threat promotion & $4.03(.82)$ & $4.27(.83)$ & .19 \\
\hline $\begin{array}{l}\text { Vulnerability } \\
\text { promotion }\end{array}$ & $3.66(.82)$ & $3.69(.74)$ & .08 \\
\hline \multicolumn{3}{|c|}{ Dichotomous parental variables } & $\operatorname{Exp}(\mathrm{B}), 95 \% \mathrm{CI}$ \\
\hline $\begin{array}{l}\text { Passivity } \\
\% \text { (n) high }\end{array}$ & $52.3(23)$ & $53.5(23)$ & $1.73, .02-190.07$ \\
\hline $\begin{array}{l}\text { Promotion of } \\
\text { avoidance } \\
\%(\mathrm{n}) \text { high }\end{array}$ & $36.4(16)$ & $41.9(18)$ & $.06, .00-9.08$ \\
\hline $\begin{array}{l}\text { Overprotection } \\
\% \text { (n) high }\end{array}$ & $31.8(14)$ & $23.3(10)$ & $.12, .001-20.95$ \\
\hline
\end{tabular}


Table 3

Correlations between maternal cognitions and behaviours

\begin{tabular}{|c|c|c|c|c|}
\hline & \multicolumn{4}{|c|}{ Behaviours } \\
\hline & $\begin{array}{c}\text { Positive } \\
\text { behaviours }\end{array}$ & Intrusiveness & $\begin{array}{c}\text { Expressed } \\
\text { anxiety }\end{array}$ & $\begin{array}{l}\text { Quality of } \\
\text { relationship }\end{array}$ \\
\hline \multicolumn{5}{|c|}{ Pretask expectations } \\
\hline $\begin{array}{l}\text { Child } \\
\text { performance }\end{array}$ & -.10 & .009 & -.05 & .15 \\
\hline $\begin{array}{l}\text { Maternal control } \\
\text { of child feelings } \\
\text { and } \\
\text { performance }\end{array}$ & -.10 & $.30 * *$ & .12 & -.15 \\
\hline \multicolumn{5}{|c|}{ Posttask evaluations } \\
\hline $\begin{array}{l}\text { Mother negative } \\
\text { emotion }\end{array}$ & -.07 & .10 & .17 & $-.24 *$ \\
\hline $\begin{array}{l}\text { Control of child } \\
\text { feelings and } \\
\text { behaviour }\end{array}$ & -.07 & .15 & .12 & -.11 \\
\hline
\end{tabular}

Comment [csc6]: Please reorder so present behaviours in same order whenever referred to. 


\subsection{Maternal pre-task expectations of child} performance/control

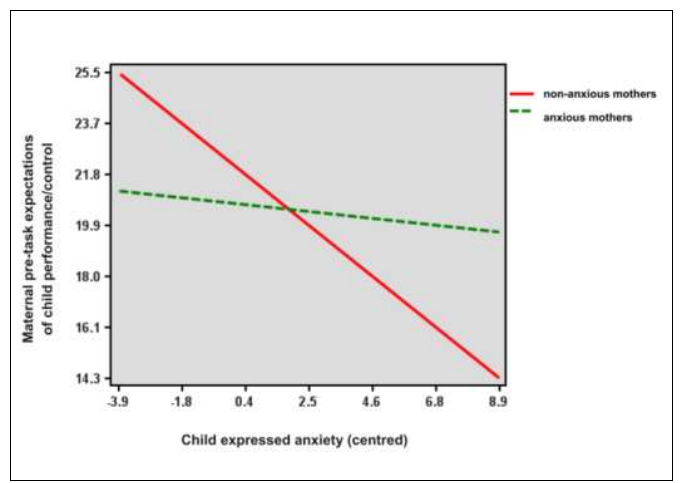

1.3. Maternal post-task ratings of own anxiety experienced during tasks

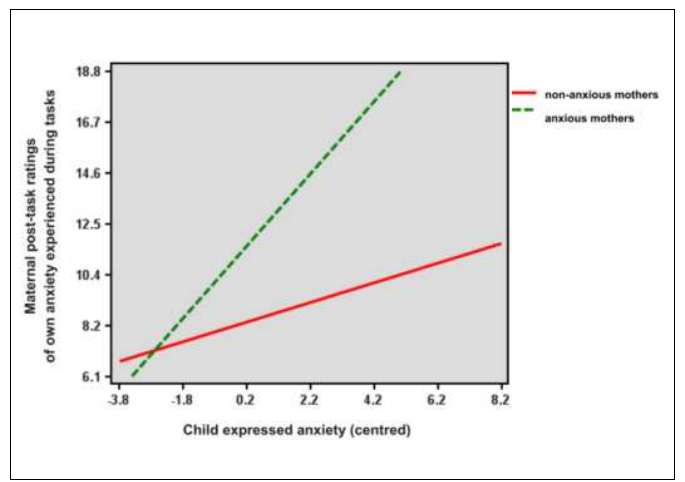

1.2. Maternal pre-task expectations of control of child feelings/performance

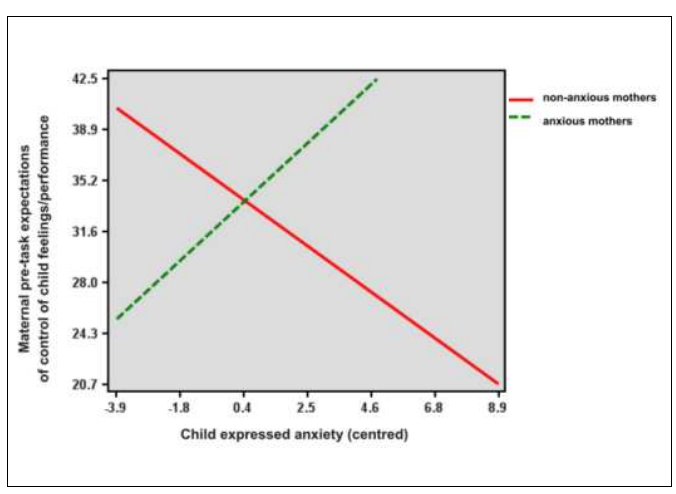

1.4. Maternal post-task ratings of control of child feelings/behaviour during tasks

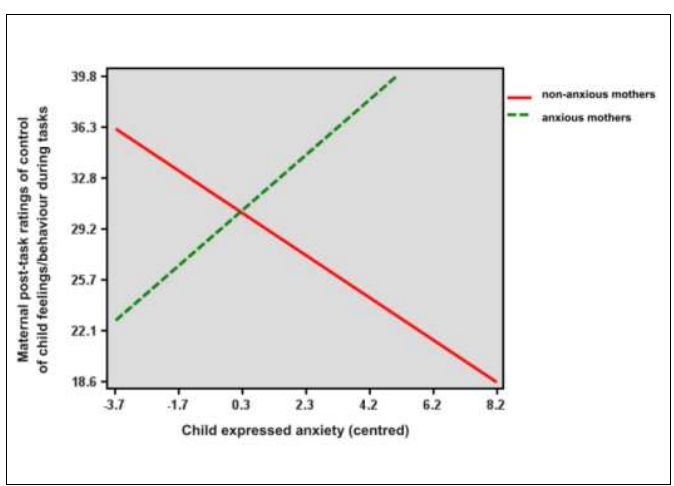


1.5. Maternal intrusiveness during tasks

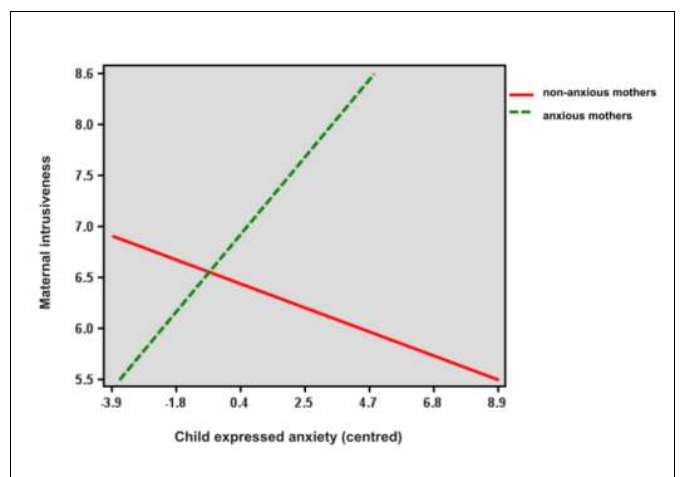

1.7. Maternal expressed anxiety during tasks

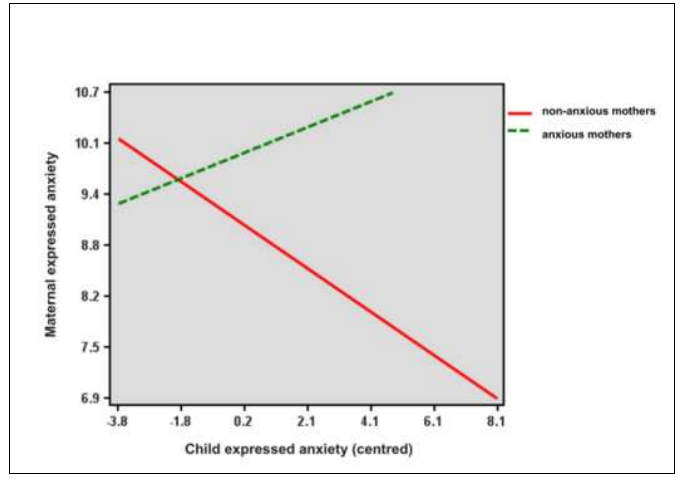

1.6. Quality of mother-child relationship during

tasks

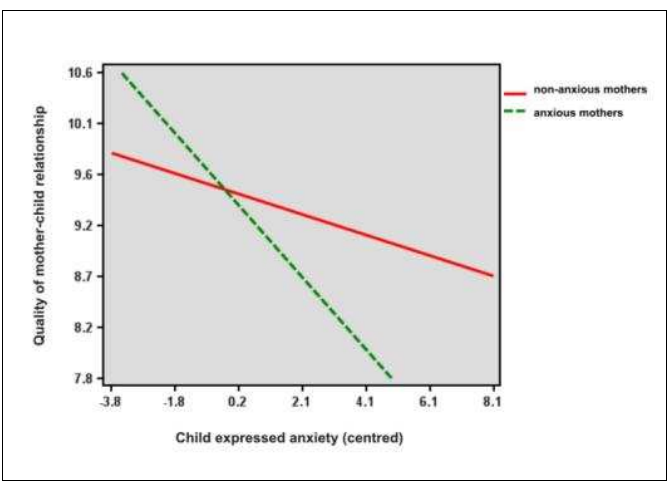

Figure 1 Interactions between maternal anxiety status and child expressed anxiety 


\section{Acknowledgements}

The authors would like that thank the participating families, as well as the assessors at the Berkshire Child Anxiety Clinic, Jenny Crosby, Amy Corcoran, Sarah Cook, Ray Percy, Sarah Shildrick, Rebecca O’Grady, Jessica Karalus, as well as Lucy Willetts, Rachel Gitau, Sue Cruddace, Mandy Lau, Michela Muggeo, Lucy Foulkes and Emma Cosham for their help with recruitment and coding data, and Cathy White for her help preparing the manuscript. 